\title{
A Rapid Method to Quantify Fungicide Sensitivity in the Brown Rot Pathogen Monilinia fructicola
}

Kerik D. Cox, Department of Plant Pathology and Plant-Microbe Biology, Barton Laboratory, New York State Agricultural Experiment Station, Cornell University, Geneva 14456; and Kacie Quello, Ryan J. Deford, and Janna L. Beckerman, Department of Botany and Plant Pathology, Purdue University, West Lafayette 47907

\begin{abstract}
Cox, K. D., Quello, K., Deford, R. J., and Beckerman, J. L. 2009. A rapid method to quantify fungicide sensitivity in the brown rot pathogen Monilinia fructicola. Plant Dis. 93:328-331.

Management of brown rot of stone fruit relies upon the application of effective fungicides that may be compromised by the development of fungicide resistance. We evaluated fungicide resistance in the brown rot pathogen, Monilinia fructicola, using Alamar blue (AB) dye, or resazurin, a chromogenic substrate that can be used as an indicator of respiration, in a 96-well microtiter format. We compared the $\mathrm{AB}$ method to traditional mycelial growth assays for resistance screening using 10 isolates of $M$. fructicola that represented a range of sensitivities to fenbuconazole. Using traditional mycelial growth assays, isolate sensitivity ranged from 17.7 to $115.3 \%$ growth on medium amended with fenbuconazole at $0.03 \mu \mathrm{g} / \mathrm{ml}$ relative to that on nonamended medium. Concordant results between both assays were obtained $\left(R^{2}=0.9943, P<0.0001\right)$, but the AB method provided results within $24 \mathrm{~h}$, as opposed to the 3- to 5-day period required for mycelial growth assays. We found that sensitive isolates reduced $A B$ less than resistant isolates in the presence of fungicide. Spore density influenced the reduction of AB by M. fructicola; spectrophotometric discrimination of fungicide sensitivity was best achieved at a density of $10^{5}$ spores/ml.
\end{abstract}

Monilinia fructicola (G. Winter) Honey, the casual agent of brown rot of stone fruit, infects the blossoms, fruit, spurs, and small branches of the tree, resulting in major economic impacts in the form of both management expenses and crop loss. The fruit rot phase of the disease is typically the most devastating to production and is most effectively managed by applications of single-site-specific fungicide chemistries such as the demethylation inhibitors (DMIs) and the quinone outside inhibitors (QoIs). Due to their highly specific mode of action, however, there is an increased propensity for DMI and QoI resistance development in $M$. fructicola populations. In $M$. fructicola, resistance to the benzimidazole fungicides was first reported in 1976 (5). The subsequent development of widespread benzimidazole resistance led to dependence on DMI fungicides in the eastern United States during the 1980s. However, at the turn of the twenty-first century, DMI-resistant $M$. fructicola populations

Corresponding author: J. L. Beckerman E-mail: jbeckerm@purdue.edu

Accepted for publication 26 November 2008.

doi:10.1094/PDIS-93-4-0328

(C) 2009 The American Phytopathological Society were reported in several of the stone-fruitgrowing regions in the eastern United States $(12,19,23)$. The QoIs are one of the few remaining classes of site-specific fungicides that provide acceptable control of the fruit rot phase and are now recommended in rotation with DMIs $(3,17)$.

Due to the high risk of pathogen populations to develop resistance to site-specific fungicides, the rapid detection of fungicide resistance in commercial orchards is essential for disease management. Testing for fungicide resistance is traditionally accomplished through the use of mycelial growth assays of single-spore isolates of the pathogen (18). This method compares the growth of isolates on fungicideamended medium relative to the growth on nonamended medium. Although this assay can conclusively identify resistance to the fungicide in question, the results cannot be quickly determined and may take several weeks for recalcitrant fungi. Such delays in the determination of fungicide sensitivity prevent growers from identifying appropriate chemical management options within the same season. Furthermore, these tests are often costly in terms of material and labor such that, when they are offered to growers as a service, they are prohibitively expensive.

Alamar blue $(\mathrm{AB})$, or resazurin, is an oxidation-reduction indicator dye, com- monly used as an indicator of microbial respiration. In the presence of actively growing cells, the resazurin indicator is changed from an oxidized, nonfluorescent blue form to a reduced, fluorescent pink form. Inhibition of growth maintains an oxidized environment, leaving the indicator blue. Several studies in medical microbiology have successfully used $A B$ to quantify both bacterial and fungal resistance to drugs used to treat human diseases $(10,11,15,21)$, and the dye is now extensively used in the medical industry for both fungal and bacterial drug testing. $\mathrm{AB}$ is nontoxic and stable, allowing long incubation periods (up to several weeks) without distorting results. As a colorimetric test, results can easily be discerned with the naked eye, or more rapid and sensitive measurements can be taken with spectroscopy equipment. Because of these favorable properties, as well as the success the dye has had in medical research, the use of $\mathrm{AB}$ to screen for fungicide resistance merits investigation.

The purpose of this study was to develop and validate an $A B$ assay routinely used in the medical microbiology community for fungicide sensitivity testing. The specific objectives of this research were to (i) use the AB technology to evaluate DMI fungicide sensitivity in M. fructicola isolates from New York and Ohio and (ii) demonstrate that this assay provides rapid, cost-effective, and accurate determinations of fungicide sensitivity.

\section{MATERIALS AND METHODS}

Fungal isolates. Ten single-conidial isolates of $M$. fructicola, representing a range of sensitivities to the DMI fungicide fenbuconazole, were used in this study (Table 1). Cultures were maintained on $20 \%$ V8 juice (Campbell's, Camden, NJ) agar (1 liter: $200 \mathrm{ml}$ of $\mathrm{V} 8$ juice and $800 \mathrm{ml}$ of $\mathrm{dH}_{2} \mathrm{O}$ ) at $22^{\circ} \mathrm{C}$ to promote conidiation. Conidia to be used for $\mathrm{AB}$ testing were harvested from 1-week-old V8 juice agar cultures by flooding the colony with $3 \mathrm{ml}$ of sterile water, rubbing the surface with a sterile rubber policeman, and collecting the spore suspension in $1.5-\mathrm{ml}$ microcentrifuge tubes. A hemacytometer was then used to quantify spore density. 
Mycelial growth assays. Isolate sensitivity to fenbuconazole was determined by a traditional mycelial growth assay as previously described (2). In short, isolates were prepared for the mycelial growth assay by spreading $20 \mu \mathrm{l}$ of conidia suspended in $10 \%$ glycerol stored at $-79^{\circ} \mathrm{C}$ on V8 agar and allowing them to grow for 3 days under the fungal isolate maintenance conditions described above. V8 juice agar (control) or V8 juice agar amended with technical-grade fenbuconazole at 0.03 $\mu \mathrm{g} / \mathrm{ml}$ (Dow AgroSciences, Indianapolis, IN) was used to test fungicide sensitivity. A discriminatory concentration of 0.03 $\mu \mathrm{g} / \mathrm{ml}$ was chosen because it represents 10 times the baseline sensitivity for fenbuconazole in New York (22). For each isolate, agar plugs containing fungal mycelium (5 $\mathrm{mm}$ in diameter) taken from the fungal colony margin were placed on amended or nonamended V8 agar plates that were then incubated for 4 days at $22^{\circ} \mathrm{C}$. The diameter of each $M$. fructicola colony was measured, and percent relative growth (RG) was calculated by dividing the diameter of the colony on the fenbuconazole-amended plate by that of the nonamended control, then multiplying this value by 100 . RG was assessed for six single-colony replicates per isolate. Isolates with mean $\mathrm{RG}$ values $<25 \%, 25$ to $75 \%$, and $>75 \%$ were categorized as sensitive, shifted, and resistant, respectively. The terminology for the category "shifted" indicates that the isolates are exhibiting some degree of quantitative resistance to fenbuconazole at 10 times the baseline $50 \%$ effective concentration for New York M. fructicola populations (22). Hence, in a population of isolates, one would say these isolates are shifted toward resistance.

AB assays. All AB assays were performed in 96-well, rounded-bottom, polystyrene microtiter plates. Each well contained $80 \mu$ l of potato dextrose broth (PDB) (VWR International, West Chester, PA) containing a defined density (see below) of M. fructicola spores. An additional $100 \mu \mathrm{l}$ of PDB amended with fenbuconazole at 0 , $0.006,0.06,0.6$, or $6.0 \mu \mathrm{g} / \mathrm{ml}$ was added to each well followed by $20 \mu \mathrm{l}$ of $\mathrm{AB}$ dye (Sigma-Aldrich, St. Louis) as an indicator of cellular respiration. The final concentrations of fenbuconazole in the test wells were $0,0.003,0.03,0.3$, or $3.0 \mu \mathrm{g} / \mathrm{ml}$.

All microtiter plates included internal standards of $\mathrm{PDB}$ and $\mathrm{AB}$ alone without M. fructicola spores, at each concentration of fenbuconazole. Plates with samples were then incubated with shaking at 300 $\mathrm{rpm}$ for $24 \mathrm{~h}$ at $22^{\circ} \mathrm{C}$. After incubation, the plate was gently shaken manually for $5 \mathrm{~s}$ to ensure homogeneity of the wells. Fungal respiration was then determined by measuring the absorbance of the dye at $570 \mathrm{~nm}$ ( $\lambda_{1}$ red reflectance, blue light absorbance) and $600 \mathrm{~nm}\left(\lambda_{2}\right.$ blue reflectance, red light absorbance) on a tunable microplate reader (Versamax, Molecular Devices, Sunnyvale,
CA). Percent reduction in $\mathrm{AB}$ was calculated by a modification of the manufacturer's equation as previously described (15): $\left(\left\{\left[\begin{array}{ll}\operatorname{\varepsilon ox} & \lambda_{2}\end{array}\right)\left(\begin{array}{ll}A & \lambda_{1}\end{array}\right)\right]-\left[\left(\begin{array}{ll}\operatorname{\varepsilon ox} & \lambda_{1}\end{array}\right)(A\right.\right.$ $\left.\left.\left.\lambda_{2}\right)\right]\right\} /\left\{\left[\left(\operatorname{cred} \lambda_{1}\right)\left(A^{\prime} \lambda_{2}\right)\right]-\left[\left(\operatorname{cred} \lambda_{2}\right)\left(A^{\prime}\right.\right.\right.$ $\left.\left.\left.\left.\lambda_{1}\right)\right]\right\}\right) \times 100$. In this equation, $\operatorname{cox}$, the molar extinction coefficient of oxidized (blue), is 117,216; sred, the molar extinction coefficient of reduced (pink), is 155,$677 ; A$ is the absorbance of test wells, $A^{\prime}$ is the absorbance of negative control wells, $\lambda_{1}$ is $570 \mathrm{~nm}$, and $\lambda_{2}$ is $600 \mathrm{~nm}$.

In order to optimize the assay, $10 \mathrm{M}$. fructicola isolates, representing distinct sensitivities to fenbuconazole as determined by the mycelial growth assay (Table 1 ), were tested at a range of spore densities ranging from $2 \times 10^{2}$ to $2 \times 10^{6}$ conidia $/ \mathrm{ml}$ to determine the effect of spore density on $\mathrm{AB}$ reduction. This assay was run both on nonamended medium (PDB) and medium amended with the discriminatory concentration of fenbuconazole at $0.03 \mu \mathrm{g} / \mathrm{ml}$ representing 10 times the baseline sensitivity of New York $M$. fructicola populations (22). Plates were prepared and measured as described above with three absorbance measurements per isolate. This experiment was repeated twice.

After optimization of the $\mathrm{AB}$ microtiter assay for spore density, all $10 \mathrm{M}$. fructicola isolates representing all three sensitivity categories were subjected to the $\mathrm{AB}$ assay at a range of fenbuconazole concentrations to determine phenotype concordance with traditional mycelial growth assays. AB microtiter plates were prepared for each isolate at fenbuconazole concentrations of $0,0.003,0.03,0.3$, or $3.0 \mu \mathrm{g} / \mathrm{ml}$ using an optimal density of $2 \times 10^{5}$ conidia/ml and measured as described above. The relationship between $A B$ reduction and $R G$ from mycelial growth assays was determined by linear regression on data from all isolates using SAS (ver. 9.13; SAS Institute, Inc., Cary, NC).

\section{RESULTS}

Mycelial growth assays. When tested at the discriminatory fenbuconazole dose of
$0.03 \mu \mathrm{g} / \mathrm{ml}$, all isolates grew to varying degrees. Percent RG across all isolates ranged from 17.7 to $115.3 \%$. Of the 10 isolates, three isolates consistently had RG values $>75 \%$ and were classified as resistant, five isolates consistently had RG values of 25 to $75 \%$ and were classified as shifted, and two isolates had RG values $<25 \%$ and were classified as sensitive (Table 1).

AB fenbuconazole sensitivity assays. At densities ranging from $10^{2}$ to $10^{4}$ conidia/ml, mean percent reduction of $\mathrm{AB}$ for resistant, shifted, and sensitive isolates was $<25 \%$ in nonamended PDB and in PDB amended with fenbuconazole at $0.03 \mu \mathrm{g} / \mathrm{ml}$ (Fig. 1A and B). At $10^{5}$ conidia/ml in nonamended $\mathrm{PDB}$, mean percent reduction of $\mathrm{AB}$ was between 23 to $43 \%$ for all isolates (Fig. 1A). At $10^{5}$ conidia/ml in PDB amended with fenbuconazole $(0.03 \mu \mathrm{g} / \mathrm{ml})$, percent reduction of $\mathrm{AB}$ varied with the isolate's sensitivity to fenbuconazole, with the resistant, shifted, and sensitive isolates having mean percent $\mathrm{AB}$ reductions of $42.12 \pm 6.8,24.72 \pm 4.0$, and $14.66 \pm$ $2.7 \%$, respectively (Fig. 1B). Using $10^{5}$ conidia also gave the most consistent visual results after $24 \mathrm{~h}$ at fenbuconazole concentrations ranging from 0.001 to 10 $\mu \mathrm{g} / \mathrm{ml}$ (Fig. 1C). Wells that turned pink indicated that respiration was occurring, demonstrating some degree of fungicide resistance, while blue wells indicated little to no respiration and fungicide sensitivity. At $10^{6}$ conidia $/ \mathrm{ml}$, isolates behaved inconsistently on fenbuconazole-amended media (Fig. 1A and B).

At $10^{5}$ conidia $/ \mathrm{ml}$, the mean percent $\mathrm{AB}$ reduction of all isolates followed a general trend of decline over the concentration range of fenbuconazole (Fig. 2A). Mean relative reduction of $\mathrm{AB}$ by the representative sensitive isolates declined from $100 \%$ with fenbuconazole at $0.0 \mu \mathrm{g} / \mathrm{ml}$ to less than $40 \%$ with fenbuconazole at 0.003 $\mu \mathrm{g} / \mathrm{ml}$. Mean relative reduction of $A B$ by the representative resistant isolates was greater than $85 \%$ at all fenbuconazole concentrations and declined only slightly

Table 1. Origin and fenbuconazole sensitivity of Monilinia fructicola isolates from New York and Ohio

\begin{tabular}{lllcc}
\hline Isolate & \multicolumn{1}{c}{ Origin } & Host & $\begin{array}{c}\text { Fenbuconazole } \\
\text { sensitivity }^{\mathbf{a}}\end{array}$ & $\begin{array}{c}\text { Sensitivity } \\
\text { classification }\end{array}$ \\
\hline NY.1B & Geneva, NY & Cherry & $112.8 \pm 4.2$ & Resistant \\
NY.2F & Geneva, NY & Cherry & $101.2 \pm 8.8$ & Resistant \\
NY.4B & Geneva, NY & Cherry & $115.3 \pm 17.8$ & Resistant \\
NY.7B & Geneva, NY & Cherry & $41.6 \pm 3.40$ & Shifted \\
NY.8C & Geneva, NY & Cherry & $39.6 \pm 5$. & Shifted \\
OH.3P & Berlin Heights, OH & Peach & $72.3 \pm 3.4$ & Shifted \\
OH.5P & Berlin Heights, OH & Peach & $53.1 \pm 5.5$ & Shifted \\
OH.7P & Rittman, OH & Peach & $24.1 \pm 3.8$ & Shifted \\
DB.58 & Olcott, NY & Peach & $19.5 \pm 1.6$ & Sensitive \\
DB.60 & Olcott, NY & Peach & $17.7 \pm 1.2$ & Sensitive \\
\hline
\end{tabular}

${ }^{a}$ Sensitivity was expressed as percent colony growth on medium amended with analytical grade fenbuconazole $(0.03 \mu \mathrm{g} / \mathrm{ml})$ relative to that on nonamended medium. Values are the means and standard errors of two colonies from two replicate plates.

${ }^{\mathrm{b}}$ Isolates with percent relative growth $\geq 75 \%$ were classified as resistant, while isolates with values between 25 and $99 \%$, and $<25 \%$ were classified as shifted and sensitive, respectively. 
with increasing concentration. Reduction of $\mathrm{AB}$ by the shifted isolates was intermediate between the sensitive and resistant isolates. Mean relative reduction of $\mathrm{AB}$ by the shifted isolates was greater than the sensitive isolate at low doses of fenbuconazole and less than the resistant isolate at higher concentrations. Similar to the quantitative effect of spore density to $A B$ reduction (Fig. 1C), these dose response relations could be distinguished both spectrophotometrically (Fig. 2A and B) and visually (Fig. 2B), whereby more respiration (pink color) was observed in wells for resistant and shifted isolates compared with sensitive isolates.
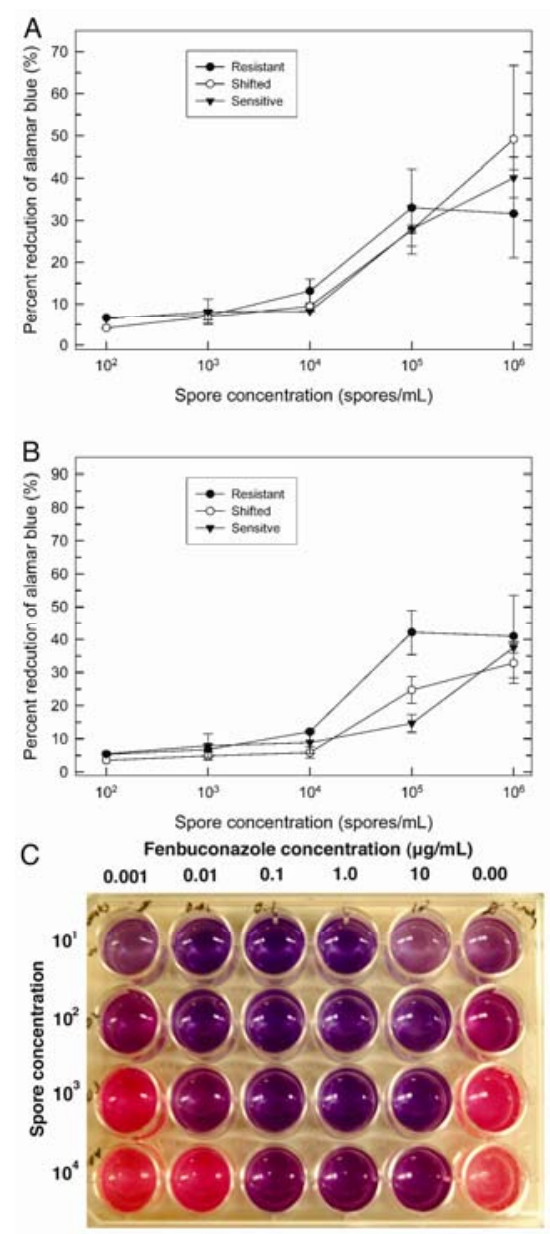

Fig. 1. Influence of spore density on the reduction of Alamar blue (AB) on $\mathbf{A}$, nonamended medium and $\mathbf{B}$, medium amended with fenbuconazole at $0.03 \mu \mathrm{g} / \mathrm{ml}$. Values are the percent $\mathrm{AB}$ reduction means and standard errors of two to five isolates in each category (resistant, shifted, or sensitive). C, Each isolate was tested on two plates with three replicate wells per isolate. $\mathrm{AB}$ assay for fungicide resistance at different spore densities after $30 \mathrm{~h}$ at fenbuconazole concentrations ranging from 0.001 to 10 $\mu \mathrm{g} / \mathrm{ml}$. The reaction of DB.58 (sensitive) assayed at different spore densities in the presence of increasing concentrations of fenbuconazole $(\mu \mathrm{g} / \mathrm{ml})$ is shown. Reduction of $\mathrm{AB}$ in respiring (living) cells results in a colorimetric reaction that turns the medium pink compared with the absence or decline of respiration in cells, which causes the medium to remain blue.
Regression of mean percent $\mathrm{AB}$ reduction on RG values determined by mycelial growth assays at the discriminatory fenbuconazole dose of $0.03 \mu \mathrm{g} / \mathrm{ml}$ indicated a strong relationship $\left(R^{2}=0.9943, P<\right.$ 0.0001 ) between both assays (Fig. 3). Isolates with low percent mean $\mathrm{AB}$ reduction (sensitive) had correspondingly low RG, while shifted and resistant isolates had correspondingly higher values for these variables.

\section{DISCUSSION}

Although considerable research has focused on elucidating the mechanisms of DMI resistance $(6-8,20,24)$, the rapid, reliable, reproducible, and inexpensive determination of resistance provides an immediate benefit to agricultural stakeholders. In this study, we were able to show that $\mathrm{AB}$ assays could accurately quantify DMI sensitivity for $M$. fructicola within $24 \mathrm{~h}$ using spectroscopy. Even without a microplate spectrophotometer, fenbuconazole sensitivity through visual differentiation could be determined. We further found that the results from $\mathrm{AB}$ assays were concordant with results obtained from mycelial growth assays. Based upon $\mathrm{AB}$ assays conducted at a range of spore concentrations, we determined that the optimal colorimetric signal occurred
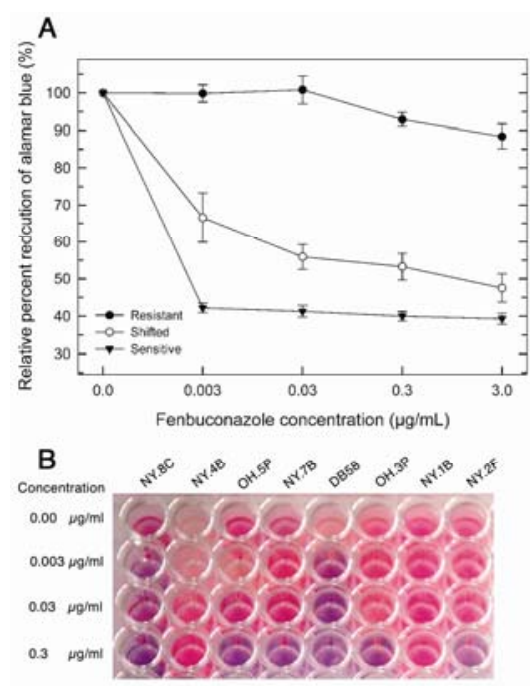

Fig. 2. Dose response of Monilinia fructicola isolates to fenbuconazole in the Alamar blue (AB) assay for fungicide resistance. A, Dose response of representative resistant, shifted, and sensitive isolates of $M$. fructicola determined by spectrometry. Values are relative percent $\mathrm{AB}$ reduction means and standard errors of two to five isolates in each category (resistant, shifted, or sensitive). Each isolate was tested on two plates and three replicate wells per isolate. Relative percent $A B$ reduction is expressed as the percent change in absorption indicative of chemical reduction in fenbuconazole amended sample wells relative to that of nonamended standards. B, Dose response reaction of select isolates to fenbuconazole is shown. Pinkcolored wells indicate fungal respiration $(\mathrm{AB}$ reduction), while blue-colored wells indicate no respiration. with M. fructicola at $10^{5}$ conidia/ml of. This spore density also produced visible results within $24 \mathrm{~h}$. This finding is similar to that of a previous study on the use of $\mathrm{AB}$ to study the germination of conidia of Botrytis cinerea (14). In both the Botrytis study and our study (data not shown), suboptimal spore densities (from $10^{2}$ to $10^{4}$ conidia/ml) required longer incubation times exceeding $24 \mathrm{~h}$. Spore densities in excess of $10^{5}$ conidia/ml produced inconsistent and unreliable results. For example, at $10^{6}$ conidia/ml in PDB amended with fenbuconazole at $0.03 \mu \mathrm{g} / \mathrm{ml}$, the sensitive isolates overcame the fungicide too quickly, and the results were indistinguishable from those in nonamended PDB. The resistant isolates showed less respiration at a density of $10^{6}$ conidia/ml than at $10^{5}$ conidia/ml, most likely indicating that the dye had already been reduced past its pink, reactive state and was changing to its clear, nonreactive state. We hypothesize that sensitivity of the dye to spore density is species dependent, and optimal spore density would have to be empirically determined to utilize this technique on different fungal pathogens. These findings are consistent with the manufacturer's (1), which notes that $\mathrm{AB}$ measures cell growth, a density-dependent phenomenon. If the cell density was too high, cell proliferation would likely decrease, resulting in less $\mathrm{AB}$ reduction than would be expected. Conversely, at a low cell density, the slower growth rate could result in insignificant $\mathrm{AB}$ reduction.

For $M$. fructicola under our growing conditions (in PDB) with a DMI fungicide, we found that spore density needed to be optimized. In cases of qualitative resistance, such as the benzimidazole fungicides, this issue may be less important.

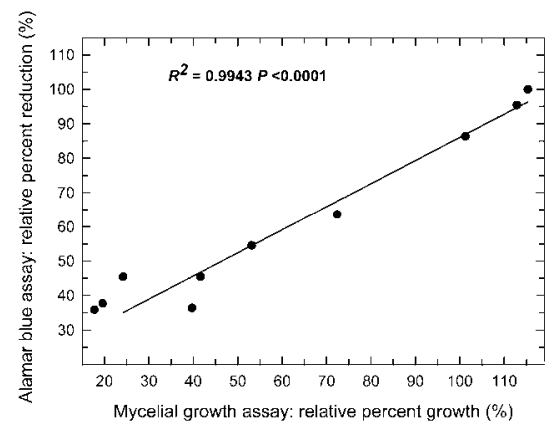

Fig. 3. Relationship between fungicide sensitivity determined by the Alamar blue (AB) assay and by mycelial growth assay for Monilinia fructicola. Fenbuconazole sensitivity determined by the mycelial growth assay is expressed as percent colony growth on medium amended with analytical-grade fenbuconazole $(0.03$ $\mu \mathrm{g} / \mathrm{ml}$ ) relative to that on nonamended medium. Relative growth values are the means of all 10 isolates with two colonies from two replicate plates. Relative percent reduction of $A B$ is expressed as the percent change in absorption indicative of chemical reduction in sample wells relative to that of an internal standard. 
However, it is hypothesized that tolerance to the killing effects of antimicrobial agents (including fungicides) increases when a large amount of inoculum is used; as expected, greater efficacy is observed when smaller amounts of inoculum are used (16). Hence, quantification and optimization of inoculum is needed for consistent high-throughput testing. In testing for susceptibility of antimicrobial agents in medicine, the amount of the starting inoculum is considered the single most important variable (9). This variable is equally important in fungicide testing.

During the mycelial growth assays, there were no indications that fenbuconazole-resistant isolates were compromised in vegetative and reproductive fitness that would affect test results (data not shown). This observation is consistent with previous reports (2). Similarly, fungal respiration in the absence of fungicide, as indicated by $\mathrm{AB}$ reduction, was not compromised in resistant compared with shifted or sensitive isolates (data not shown).

As with the mycelial growth assay, this $\mathrm{AB}$ assay can be used to quantify fungicide sensitivity phenotypes but is incapable of identifying the genotype and does not provide an alternative to polymerase chain reaction-based studies to identify genes that confer fungicide resistance. Another disadvantage of this method is the reliance on quantifiable reproductive propagules such as spores, and it may not be useful for assaying fungicide sensitivity in pathogens that do not readily sporulate in culture. Finally, the presence of possible contaminant yeast and bacteria on the surface of fungal hyphae or infected plant tissue prevents the assay from being used directly on field samples. One could easily envision that differences in surface contaminants could skew $\mathrm{AB}$ respiration determination of fungi removed from field samples. Because of these concerns, only pure cultures of sporulating fungal pathogens would be amendable to this technique. However, our $\mathrm{AB}$ assay still evaluates the phenotype of fungicide resistance within $24 \mathrm{~h}$ compared with 3 to 5 days for mycelial growth assays. Aside from the improved speed of the assay, this approach may improve fungicide sensitivity screening in several other ways. The microtiter plates potentially allow for a high-throughput screening of multiple isolates, multiple fungicides, and multiple fungicide concentrations to be assayed in as little as $2 \mathrm{~h}$ following isolate preparation and the $24 \mathrm{~h}$ incubation. Collection of results was less time consuming, because a 96-well plate reader took absorbance readings in a matter of seconds as opposed to the mycelial growth assays, which require manual measurement of colony diameter. Similarly, reduced assay times were previously reported with $\mathrm{AB}$ compared with other methods on several fungal species (13). In our study, material costs for $\mathrm{AB}$ assays were also much lower than those for poison agar tests. We calculated the cost of 96 reactions, excluding labor, to be under $\$ 4$ per isolate for $\mathrm{AB}$ assays and over $\$ 15$ per isolate for mycelial growth assays. The cost of the $\mathrm{AB}$ assays was based on buying the powdered reagent and preparing the dye solutions in the lab as opposed to buying prepared dye.

In summary, we found that the $\mathrm{AB}$ method is a faster, less expensive alternative to mycelial growth assays for $M$. fructicola. This assay may be a more reliable indicator of fungicide resistance because it uses spores instead of mycelia (4). Furthermore, it can provide stone fruit growers with needed information about the sensitivity of isolates collected from their orchards in a more cost-effective manner. The technology also adds simplicity to the detection of resistance, especially when quantification is not desired, and results can be taken visually.

\section{ACKNOWLEDGMENTS}

We thank M. A. Ellis for providing isolates from Ohio for this study and L. Dunkle, S. Goodwin, and G. Shaner for editorial and scientific comments on the manuscript. This work was supported by startup funds from Purdue University.

\section{LITERATURE CITED}

1. Anonymous. 2002. AlamarBlue technical data sheet. at: http://www.ab-direct.com/uploads/ BUF012-technical-datasheet-2008.pdf. AbD Serotec Ltd., Oxford, UK

2. Cox, K. D., Bryson, P. K., and Schnabel, G. 2007. Instability of propiconazole resistance and fitness in Monilinia fructicola. Phytopathology 97:448-453.

3. Cox, K. D., Köller, W., and Rosenberger, D. A. 2007. Making 'The Best' last: controlling brown rot in the face of fungicide resistance. Scaffolds 16:3-5.

4. Hu, J., Hong, C., Stromberg, E. L., and Moorman, G. W. 2007. Effects of propamocarb hydrochloride on mycelial growth, sporulation, and Infection by Phytophthora nicotianae isolates from Virginia nurseries. Plant Dis. 91 (4):414-420.

5. Jones, A. L., and Ehret, G. R. 1976. Isolation and characterization of benomyl tolerant strains of Monilinia fructicola. Plant Dis. Rep. 60:765-769.

6. Koenraadt, H., Somerville, S. C., and Jones, A. L. 1992. Characterization of mutations in the beta-tubulin gene of benomyl-resistant field strains of Venturia inaequalis and other plant pathogenic fungi. Phytopathology 82:13481354.

7. Luo, C.-X., and Schnabel, G. 2008. Adaptation to fungicides in Monilinia fructicola isolates with different fungicide resistance phenotypes. Phytopathology 98:230-238.

8. Ma, Z., and Michailides, T. J. 2005. Advances in understanding molecular mechanisms of fungicide resistance and molecular detection of resistant genotypes in phytopathogenic fungi. Crop Prot. 24:853-863.
9. NCCLS. 1998. Methods for Determining Bactericidal Activity of Antimicrobial Agents. Approved Guideline M26-A. National Committee for Clinical Laboratory Standards, Wayne, PA.

10. O'Brien, J., Wilson, I., Orton, T., and Pognan, F. 2000. Investigation of the alamar blue (resazurin) fluorescent dye for the assessment of mammalian cell cytotoxicity. Eur. J. Biochem. 267:5421-5426.

11. Page, B., Page, M., and Noel, C. 1993. A new fluorometric assay for colorimetric cytotoxicity measurements in vitro. Int. J. Oncol. 3:473476.

12. Parker, D. M., Zhang, N., Smart, C. D., and Köller, W. 2006. Polymorphism of 14-alpha demythylase gene (CYP51) in brown rot pathogen Monilinia fructicola from a resistant orchard in New York State. (Abstr.) Phytopathology 96:S90.

13. Patel, R., Mendrick, C., Knapp, C., Grist, R., and McNicholas, P. 2007. Clinical evaluation of the sensititre YeastOne plate for testing susceptibility of filamentous fungi to posaconazole. J. Clin. Microbiol. 45:2000-2001.

14. Pelloux-Prayer, A., Priem, B., and Joseleau, J. 1998. Kinetic evaluation of conidial germination of Botrytis cinerea by a spectrofluorometric method. Mycol. Res. 102:320 322.

15. Pettit, R., Weber, C., Kean, M., Hoffmann, H., Pettit, G., Tan, R., Franks, K., and Hortons, M. 2005. Microplate alamar blue assay for Staphylococcus epidermidis biofilm susceptibility testing. Antimicrob. Agents Chemother. 49:2612-2617.

16. Pfaller, M. A., Sheehan, D. J., and Rex, J. H. 2004. Determination of fungicidal activities against yeasts and molds: lessons learned from bactericidal testing and the need for standardization. Clin. Microbiol. Rev. 17:268-280.

17. Rosenberger, D. A., and Cox, K. D. 2008. Disease management. In: 2008 Pest Management Guidelines for Commercial Tree-Fruit Production. A. M. Agnello, ed. Cornell University Cooperative Extension, Ithaca, NY

18. Russell, P. E. 2004. Sensitivity baselines in fungicide resistance research and management. http://www.frac.info/frac/publication/anhang/ monograph3.pdf.

19. Schnabel, G., Bryson, P. K., Bridges, W. C., and Brannen, P. 2004. Reduced sensitivity in Monilinia fructicola to propiconazole in Georgia and implications for disease management. Plant Dis. 88:1000-1004.

20. Schnabel, G., and Jones, A. L. 2001. The $14 \alpha \cdot$ Demethylase (CYP51A1) gene is overexpressed in Venturia inaequalis strains resistant to myclobutanil. Phytopathology 91:102110 .

21. To, W., Fothergill, A., and Rinaldi, M. 1995. Comparative evaluation of macrodilution and Alamar colorimetric microdilution broth methods for antifungal susceptibility testing of yeast isolates. J. Clin. Microbiol. 33:26602664.

22. Wilcox, W. F., and Burr, J. A. 1994. Base-line sensitivity of Monilinia fructicola to six DMI fungicides. (Abstr.) Phytopathology 84:1078.

23. Zehr, E., Luszcz, L. A., Olien, W. C., Newall, W. C., and Toler, J. E. 1999. Reduced sensitivity in Monilinia fructicola to propiconazole following prolonged exposure in peach orchards. Plant Dis. 83:913-916.

24. Zheng, D., and Köller, W. 1997. Characterization of the mitochondrial cytochrome $b$ gene from Venturia inaequalis. Curr. Genet. 32:361366. 